\title{
FORMULATION AND STABILITY ASSESSMENT OF ARABICA AND CIVET COFFEE EXTRACTS BASED COSMETIC PREPARATIONS
}

\section{CHAIYAVAT CHAIYASUT ${ }^{1}$, BHAGAVATHI SUNDARAM SIVAMARUTHI ${ }^{1}$, SASITHORN SIRILUN ${ }^{1}$, NETNAPA MAKHAMRUEANG ${ }^{1}$, JAKKAPAN SIRITHUNYALUG ${ }^{1}$, SARTJIN PEERAJAN ${ }^{2}$, PERIYANAINA KESIKA ${ }^{1 *}$}

${ }^{1}$ Innovation Center for Holistic Health, Nutraceuticals and Cosmeceuticals, Faculty of Pharmacy, Chiang Mai University, Chiang Mai 50200, Thailand. ${ }^{2}$ Health Innovation Institute, Chiang Mai, 50200, Thailand. Email: p.kesika@gmail.com

Received: 28 February 2018, Revised and Accepted: 27 August 2018

ABSTRACT

Objective: The coffee is one of the most common beverages with reported health benefits. The coffee extracts are used in cosmetic and pharmacological preparations. The present study deals with the development of Arabica and Civet coffee extract based cosmetic formulas and its stability.

Methods: Coffee extracts were prepared by mechanical pressing and solvent extraction methods. The total phenolic content of the extracts was assessed by Folin-Ciocalteu colorimetric method. The body lotion (BL) and hand moisturizing cream (HMC) were formulated, and the stability, heavy metal, and microbial contamination of the products stored at different temperatures for 3 months were evaluated by the organoleptic method, atomic absorption spectrophotometer, and plate assay, respectively.

Results: The developed products (BL and HMC) were creamy, slightly dark in color with coffee fragrance. The products were stable, and no changes in color, odor, and texture were observed, for 3 months even at $40^{\circ} \mathrm{C}$. BL was found to be not contaminated with lead, whereas, the presence of arsenic and mercury were found in the concentration of $<0.16$ and $<0.09 \mathrm{mg} / \mathrm{kg}$, respectively. The HMC has $<0.16 \mathrm{mg} / \mathrm{kg}$ of arsenic and $<0.09-0.28 \mathrm{mg} / \mathrm{kg}$ of mercury, while no lead content was detected. BL and HMC harbor only 253-281 and 231-251 CFU/g, respectively. The products were free from pathogenic microbes. The extract method has not affected the quality of the product.

Conclusion: The BL and HMC were stable and contain negligible amount of heavy metal and found to be microbiologically safe. The presence of coffee extract in the products nourishes and protects the skin and suitable for topical applications.

Keywords: Arabica coffee, Civet coffee, Phenolic compound, Body lotion, Hand moisturizing cream, Heavy metal.

(C) 2018 The Authors. Published by Innovare Academic Sciences Pvt Ltd. This is an open access article under the CC BY license (http://creativecommons. org/licenses/by/4. 0/) DOI: http://dx.doi.org/10.22159/ajpcr.2018.v11i6.25522

\section{INTRODUCTION}

The coffee is one of the most common beverages around the world and majorly cultivated in Kenya, Brazil, Ethiopia, Jamaica, Hawaii, and Vietnam. The genus Coffea contains $\sim 70$ species. Coffea arabica and Coffea canephora var. Robusta are the economically important coffee varieties. Almost $60 \%$ of coffee production is contributed by C. arabica, commonly known as Arabica coffee (AC) [1]. AC is superior in the aroma and cup quality, while Robusta is rich in flavor, soluble solids, caffeine, and other antioxidants [2]. The chemical composition of coffee brew varied on several factors such as cultivation condition and processing such as roasting and grinding. The roasting of coffee bean is a critical step, which affects the final qualities (aroma, color, taste, and phytochemical content) of the coffee [3].

Green coffee contains $60 \%$ of carbohydrates (stachyose, raffinose, sucrose, cellulose, arabinogalactan, galactomannan, arabinose, glucose, galactose, fructose, mannitol, mannose, xylose, and ribose), 8-18\% of protein, lipids (triglyceride, stigmasterol, and sitosterol), fatty acids (oleic, linoleic, palmitic, linolenic, arachidic, stearic, behenic, and lignoceric), and polyphenols (caffeoylquinic, feruloylquinic, cinnamoylquinic, and dicaffeoylquinic acids). Asparagine, alanine, glutamic acid, lysine, and aspartic acid are the primary amino acid constituents of coffee. The coffee is rich in caffeine, trigonelline, theophylline, and theobromine [4-6].

Civet coffee (CC) is the oddest and expensive coffee in the world due to its extensive processing and unique taste. CC is prepared using any coffee bean (Arabica or Robusta). Asian palm civet (Paradoxurus hermaphroditus) was fed with coffee beans, and the beans were partially digested in the intestinal tract of the animal. The digested beans have been collected during defecation and subjected to routine processing such as drying, dehulling, and roasting. The partial fermentation and digestion process reduced the bitterness and improved the aroma of the coffee [7].

Although coffee is a common refreshing beverage, recent studies revealed that the consumption of coffee reduced the prevalence of several diseases such as diabetes, cardiovascular diseases, cancer, and Parkinson's disease. Acute coffee consumption improved the plasma antioxidant capacity [8]. The coffee and caffeine-based cosmetic preparations are available in the market due to its beneficial health activity and ability to penetrate the skin barrier. The cosmetic formulas meant for topical applications such as anti-cellulite products contain caffeine to prevent the body from excess accumulation of fat [9].

The aim of the present study was to formulate body lotion (BL) and hand moisturizing cream (HMC) containing $\mathrm{AC}$ and CC extract. We have successfully formulated the BL and HMC, and the stability, chemical, and microbiological safety of the formulated products was evaluated.

\section{METHODS}

\section{Sample collection and extraction}

Two different types of coffee beans (Arabica and Civet) were collected from Ban Dong Coffee manufactures, Mae Hong Son, Thailand (Fig. 1). $\mathrm{AC}$ and $\mathrm{CC}$ beans were ground using coffee grinder and then subjected to two different extraction procedures such as solvent extraction using propylene glycol and coffee machine extraction. Coffee powder was mixed with $80 \%$ propylene glycol at the ratio of 1:10 and incubated in shaker for $24 \mathrm{~h}$ at $180 \mathrm{rpm}$. Then, the extract was filtered through 
Whatman filter paper No. 1 and stored at $4^{\circ} \mathrm{C}$ until use. For coffee machine-based extraction, coffee powder and water were mixed at the ratio of 1:10 and extracted using coffee maker (Nuova Simonelli $\AA$, Model no. APPIA II). The extract was stored in amber bottle at $4^{\circ} \mathrm{C}$ until use.

\section{Total phenolic content (TPC)}

The TPC of the coffee extracts was determined by Folin-Ciocalteu colorimetric method as prescribed previously [10], and TPC was denoted as mg of gallic acid equivalent (GAE) per g of sample.

\section{Preparation of BL and HMC}

The Phase A ingredients (Olivem ${ }^{\circledR}$ 1000, Oliwax ${ }^{\circledR}$, butylated hydroxytoluene, cyclopentasiloxane and cyclohexasiloxane, neopentyl glycol diheptanoate (NGD) and isododecane (ID), caprylic/capric triglyceride, and dimethicone), and Phase B ingredients (glycerine, EDTA, Glydant ${ }^{\circledR}$, Euxyl K120®, Euxyl PE9010®, Vitamin E acetate, coenzyme Q10, and water) were prepared separately and then both the Phases (A and $\mathrm{B}$ ) were mixed together at $70-75^{\circ} \mathrm{C}$ until it gets mixed well to reach the desired texture. Then, the mixture was allowed to cool (to reach room temperature), and then different concentrations of coffee extracts (Formula 1, 2, and 3 contains 0,5 , and $10 \%$ of coffee extract) were mixed. Both BL and HMC contain the same ingredients except Vitamin E acetate and coenzyme Q10 that was not used in HMC. The concentration of ingredients used for the preparation of products in the present study was standardized by the Health Innovation Institute, Chiang Mai, Thailand, and all the rights were reserved as company secrets.

\section{Characterization of the products}

The physical (color, odor, and texture), chemical (pH and heavy metals such as lead, arsenic, and mercury), and biological characteristics of the product were determined by organoleptic method [11,12], atomic absorption spectrophotometer [13], and plate assay [14,15], respectively, as detailed previously.

\section{Stability assessment}

The stability of the products was assessed after storing the products at different temperatures $\left(4,30\right.$, and $\left.40^{\circ} \mathrm{C}\right)$ for 3 months. After 3 months of storage, the color, odor, and texture of the product and contamination in the preparations were determined.

\section{Statistical analysis}

All the experiments were performed in triplicates, and the values were represented as mean \pm standard deviation.

\section{RESULTS AND DISCUSSION}

$\mathrm{AC}$ and $\mathrm{CC}$ beans were extracted using $80 \%$ propylene glycol and coffee machine. The TPC of AC and CC coffee machine extracts was $11.81 \pm 0.86$ and $10.34 \pm 0.31 \mathrm{mg} \mathrm{GAE} / \mathrm{g}$ sample, respectively. Similarly, TPC of propylene glycol extract of AC and CC was $10.03 \pm 1.75$ and $10.67 \pm 1.00 \mathrm{mg} \mathrm{GAE} / \mathrm{g}$ sample, respectively (Table 1 ).

The BL and HMC were formulated with a different concentration of coffee extracts (5 or 10\%) as described in materials and methods section. Olivem ${ }^{\circledR} 1000$ is apolyethylene glycol-free vegetable selfemulsifying agent, chemically comparable to lipid composition of the skin surface, commonly used in topical creams. Oliwax is a stabilizing lipid derived from olive oil. Its spreadability and smoothness are appropriate for several cosmetic products, especially for hair and skin care products. Butylated hydroxytoluene was used as a preservative in the preparation. Cyclopentasiloxane and cyclohexasiloxane were used as a skin conditioning and delivery agent, emollient, solvent, and lubricant. NGD and ID are used as emollient in skin care products. NGD is an excellent alternative to silicones, and NGD is smooth and velvety on the skin. ID is a low viscous, high spreadable, and fragrant agent for lotion-based products.

Caprylic/capric triglycerides are an oily liquid triester derived from coconut oil and glycerin, and it is used as an emollient, solvent, and dispersing agent. Dimethicone is the potent anti-foaming agent, commonly used in cosmetic products, especially in conditioners. Glydant ${ }^{\circledR} 2000$ and euxyl ${ }^{\circledR}$ K 120 act as a liquid cosmetic preservative, which is active against bacteria, yeasts, and fungi. In the present study, we have used all the necessary ingredients in a scientifically proven ratio (the results of optimization of cosmetic compounds are unrevealed in this manuscript since the information was protected as private industrial secret) to formulate the high-quality cosmetic formulation.

The initial color, odor, and texture of both BL and HMC was uniform light brown, caffeine, and homogeneous, respectively. The color intensity was high in the formula with high concentration of coffee extract. The formulas are not distinguishable based on the appearance since both the products are containing AC extract and CC extract (Figs. 2 and 3).

The formulas were stored at different temperatures $\left(4,30\right.$, and $\left.40^{\circ} \mathrm{C}\right)$ for 3 months to assess the stability of the product. The color and odor of the product were scored with 1-3 (1 - irregular color, 2 - medium uniformity in color, and 3 - uniform color; 1- Bad smell, 2 - alight change in original odor, and 3 - good). All the samples stayed excellent and fresh even after 3 months of storage. The storage temperature has not affected the quality of the product. The texture of the product was not changed. No clumps and watering were observed in the products (Table 2 ).

The initial $\mathrm{pH}$ of the product was 5 , and the $\mathrm{pH}$ of both BL and HMC was not changed after 3 months of storage at various temperatures (Table 3). The $\mathrm{pH}$ of the skin is ranging from 4 to 5.5. The skincare products with the $\mathrm{pH}$ of normal skin are preferable.

The heavy metal content of BL and HMC was assessed. The results showed that BL was not contaminated with lead, whereas the presence of arsenic and mercury was found in the concentration of about $<0.16$ and $<0.09 \mathrm{mg} / \mathrm{kg}$, respectively. The HMC has $<0.16 \mathrm{mg} / \mathrm{kg}$ of arsenic and $<0.09-0.28 \mathrm{mg} / \mathrm{kg}$ of mercury, while no lead content was detected (Table 4). According to Thai Industrial Standard (TIS 478-2555), the concentration of lead, arsenic, and mercury should be $<20,5$, and $1 \mathrm{mg} / \mathrm{kg}$ of product, respectively. Both BL and HMC contain only trace amount of arsenic and mercury, while no lead content was detected.

The microbiological safety of BL and HMC was determined. The results proved that BL and HMC harbor only 253-281 and 231-251 CFU/g, respectively. The content of representative pathogenic microbes (Candida albicans, Pseudomonas aeruginosa, Staphylococcus aureus, and Clostridium spp.) in cosmetic formulas was also studied. No pathogens were found in both the products after 3 months of storage at $40^{\circ} \mathrm{C}$

Table 1: The TPC of AC and CC extracts

\begin{tabular}{lll}
\hline Types of coffee & $\begin{array}{l}\text { Extraction } \\
\text { method }\end{array}$ & $\begin{array}{l}\text { TPC (mg GAE/g } \\
\text { sample) }\end{array}$ \\
\hline AC & Coffee machine & $11.81 \pm 0.86$ \\
& Propylene glycol & $10.03 \pm 1.75$ \\
CC & Coffee machine & $10.34 \pm 0.31$ \\
& Propylene glycol & $10.67 \pm 1.00$ \\
\hline
\end{tabular}

TPC: Total phenolic content, AC: Arabica coffee, CC: Civet coffee

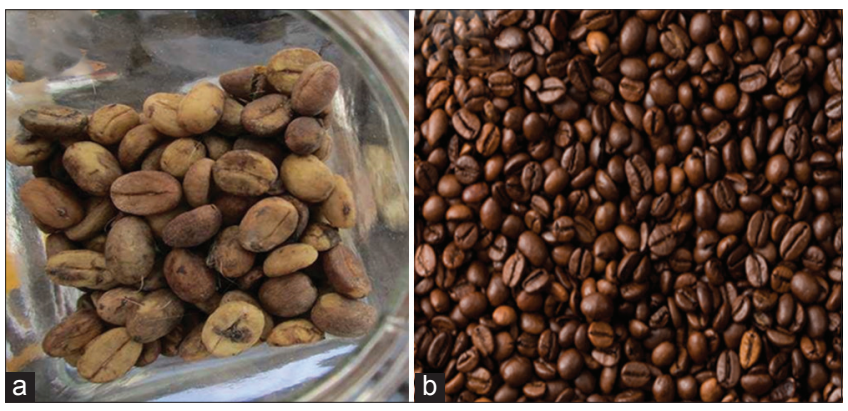

Fig. 1: The collected coffee bean samples. (a) Civet coffee, (b) Arabica coffee 
Table 2: The physical characteristics (color, odor, and texture) of the body lotion and hand moisturizing cream

\begin{tabular}{|c|c|c|c|c|c|c|c|c|c|c|c|c|}
\hline \multirow[t]{3}{*}{ Products } & \multirow[t]{3}{*}{ Formula } & \multirow[t]{3}{*}{ Extract } & \multirow[t]{3}{*}{ Temperature $\left({ }^{\circ} \mathrm{C}\right)$} & \multirow{2}{*}{\multicolumn{4}{|c|}{$\begin{array}{l}\text { Color } \\
\text { Month }\end{array}$}} & \multirow{2}{*}{\multicolumn{4}{|c|}{$\begin{array}{l}\text { Odor } \\
\text { Month }\end{array}$}} & \multirow{3}{*}{$\begin{array}{l}\text { Texture } \\
\text { Month (0-3) }\end{array}$} \\
\hline & & & & & & & & & & & & \\
\hline & & & & $\mathbf{0}$ & 1 & 2 & 3 & $\mathbf{0}$ & 1 & 2 & 3 & \\
\hline \multirow[t]{16}{*}{$\mathrm{BL}$, and $\mathrm{HMC}$} & 1 & $\mathrm{AC}$ & 4 & 3 & 3 & 3 & 3 & 3 & 3 & 3 & 3 & \multirow[t]{16}{*}{ Smooth, and uniform texture } \\
\hline & & & 30 & 3 & 3 & 3 & 3 & 3 & 3 & 3 & 3 & \\
\hline & & & 40 & 3 & 3 & 3 & 3 & 3 & 3 & 3 & 3 & \\
\hline & & $\mathrm{CC}$ & 4 & 3 & 3 & 3 & 3 & 3 & 3 & 3 & 3 & \\
\hline & & & 40 & 3 & 3 & 3 & 3 & 3 & 3 & 3 & 3 & \\
\hline & 2 & AC & 4 & 3 & 3 & 3 & 3 & 3 & 3 & 3 & 3 & \\
\hline & & & 30 & 3 & 3 & 3 & 3 & 3 & 3 & 3 & 3 & \\
\hline & & & 40 & 3 & 3 & 3 & 3 & 3 & 3 & 3 & 3 & \\
\hline & & CC & 4 & 3 & 3 & 3 & 3 & 3 & 3 & 3 & 3 & \\
\hline & & & 30 & 3 & 3 & 3 & 3 & 3 & 3 & 3 & 3 & \\
\hline & & & 40 & 3 & 3 & 3 & 3 & 3 & 3 & 3 & 3 & \\
\hline & 3 & $\mathrm{AC}$ & 4 & 3 & 3 & 3 & 3 & 3 & 3 & 3 & 3 & \\
\hline & & & 40 & 3 & 3 & 3 & 3 & 3 & 3 & 3 & 3 & \\
\hline & & $\mathrm{CC}$ & 4 & 3 & 3 & 3 & 3 & 3 & 3 & 3 & 3 & \\
\hline & & & 30 & 3 & 3 & 3 & 3 & 3 & 3 & 3 & 3 & \\
\hline & & & 40 & 3 & 3 & 3 & 3 & 3 & 3 & 3 & 3 & \\
\hline
\end{tabular}

Color score: 1 - irregular color, 2 - medium uniformity in color, 3 - uniform color, Odor score: 1 - bad, 2 - slight change in odor, 3 - good, BL: Body lotion, HMC: Hand moisturizing cream, AC: Arabica coffee, CC: Civet coffee

Table 3: $\mathrm{pH}$ of the body lotion and hand cream products stored at different temperature for 3 months

\begin{tabular}{|c|c|c|c|c|}
\hline Product & Formula & Extracts & $\begin{array}{l}\text { Temperature } \\
\left({ }^{\circ} \mathrm{C}\right)\end{array}$ & $\begin{array}{l}\text { pH during } \\
\text { 0-3 months }\end{array}$ \\
\hline \multirow[t]{18}{*}{ BL and HMC } & 1 & $\mathrm{AC}$ & 4 & 5 \\
\hline & & & 30 & \\
\hline & & & 40 & \\
\hline & & $\mathrm{CC}$ & 4 & 5 \\
\hline & & & 30 & \\
\hline & & & 40 & \\
\hline & 2 & $\mathrm{AC}$ & 4 & 5 \\
\hline & & & 30 & \\
\hline & & & 40 & \\
\hline & & $\mathrm{CC}$ & 4 & 5 \\
\hline & & & 30 & \\
\hline & & & 40 & \\
\hline & 3 & $\mathrm{AC}$ & 4 & 5 \\
\hline & & & 30 & \\
\hline & & & 40 & \\
\hline & & $\mathrm{CC}$ & 4 & 5 \\
\hline & & & 30 & \\
\hline & & & 40 & \\
\hline
\end{tabular}

BL: Body lotion, HMC: Hand moisturizing cream, AC: Arabica coffee, CC: Civet coffee

(Table 5). According to the United State Pharmacopoeia (USP) and TIS act (TIS 478-2555), the skin care product should not contain pathogenic bacteria (S. aureus, P. aeruginosa, C. albicans, and Clostridium spp.), and the total bacterial count should not exceed 1000 colonies per gram or cubic centimeter. The BL and HMC were found to be microbiologically safe.

Several studies have proved that caffeine has anti-cellulite and antifibrotic properties, increases the metabolism, lipolysis, hair growth, and microcirculation of the blood, decreases puffy eyes, quickens the lymph drainage from fatty tissue, and helps to remove toxins from the system. Thus, caffeine and coffee extracts are used in various cosmetic products $[9,16,17]$. The consumption of coffee has been reported to maintain the level of urine uric acid [18].
The aqueous extract of coffee silverskin (a byproduct of coffee roasting process) has been examined for the antiaging properties using in vitro and in vivo model system. The results suggested that coffee silverskin extract protects the human keratinocytes from oxidative damages and extends the lifespan of Caenorhabditis elegans [19]. Rodrigues et al. [20] proved that coffee silverskin was a cosmetically significant candidate with high antioxidant and antimicrobial property with no cytotoxicity to human cells. The coffee silverskin extracts and green coffee oil were safe for topical applications $[21,22]$

The used coffee grounds are a best renewable alternative source of bioactive principles. The used coffee powder contains kahweol, cafestol, trigonelline, caffeine, and polyphenolic compounds (gallic acid, protocatechuic acid, and chlorogenic acid) and exhibited high antioxidant activity. The study suggested that the bioactive compounds of used coffee powder are effective ingredients in cosmetic and pharmaceutical preparations and can be used in functional foods [23,24]. Several studies have revealed the antioxidant richness of raw and used coffee and its extracts [25-27]. The microencapsulated green coffee oil has been considered as a promising, antioxidants rich cosmeceutical agent, and it is proved that skin cream containing used coffee ground oil improved the skin sebum levels $[27,28]$.

\section{CONCLUSION}

The AC and CC extract based BL and HMC were developed. Significant changes were not observed among the product containing solvent and mechanically extracted coffee, in terms of product stability, appearance, and TPC. The products were stable for 3 months at different storage temperatures and were found to be free from tested heavy metals and pathogenic microbes. Further, clinical studies are required to know the consumer satisfaction on the products.

\section{ACKNOWLEDGMENT}

Authors gratefully acknowledge Science, Technology, and Innovation Coupon for OTOP Upgrade Project (Ministry of Science and Technology and Clinic Technology, Chiang Mai University), the Faculty of Pharmacy, and Chiang Mai University, Thailand. PK would like to acknowledge the CMU-Post Doctoral Fellowship for the necessary support.

\section{AUTHOR'S CONTRIBUTIONS}

CC involved in the study design, experiments, review, and finalization of the manuscript. BSS and PK contributed to data analysis, manuscript 
Table 4: HMC in body lotion and hand cream after stoage at $40^{\circ} \mathrm{C}$ for 3 months

\begin{tabular}{|c|c|c|c|c|c|}
\hline \multirow[t]{2}{*}{ Product } & \multirow[t]{2}{*}{ Formula } & \multirow[t]{2}{*}{ Extracts } & \multicolumn{3}{|l|}{ Heavy metal } \\
\hline & & & Lead (mg/kg) & Arsenic (mg/kg) & Mercury (mg/kg) \\
\hline $\mathrm{BL}$ & $\begin{array}{l}1 \\
2 \\
3\end{array}$ & $\begin{array}{l}- \\
\mathrm{AC} \\
\mathrm{CC} \\
\mathrm{AC} \\
\mathrm{CC}\end{array}$ & Not detected & $<0.16$ & $<0.09$ \\
\hline HMC & $\begin{array}{l}1 \\
2 \\
3\end{array}$ & $\begin{array}{l}- \\
\text { AC } \\
\text { CC } \\
\text { AC } \\
\text { CC }\end{array}$ & Not detected & $<0.16$ & $\begin{array}{l}<0.28 \\
<0.09 \\
<0.28 \\
<0.09 \\
<0.28\end{array}$ \\
\hline
\end{tabular}

BL: Body lotion, HMC: Hand moisturizing cream, AC: Arabica coffee, CC: Civet coffee

Table 5: The microbiological assessment of $\mathrm{BL}$ and $\mathrm{HMC}$ after storage at $40^{\circ} \mathrm{C}$ for 3 months

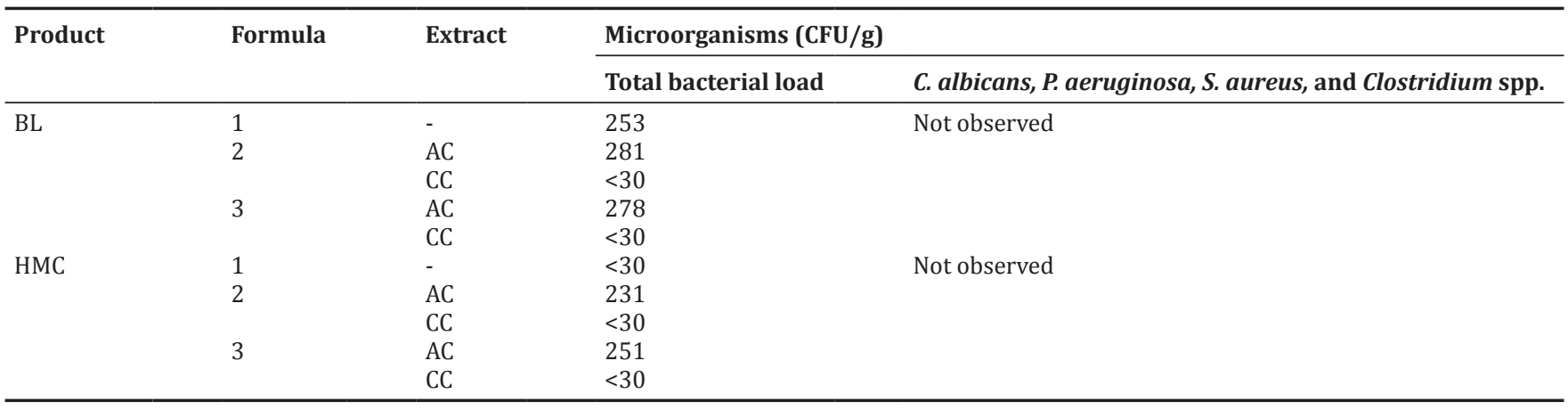

BL: Body lotion, HMC: Hand moisturizing cream, AC: Arabica coffee, CC: Civet coffee, C. albicans: Candida albicans, P. aeruginosa: Pseudomonas aeruginosa, S. aureus: Staphylococcus aureus

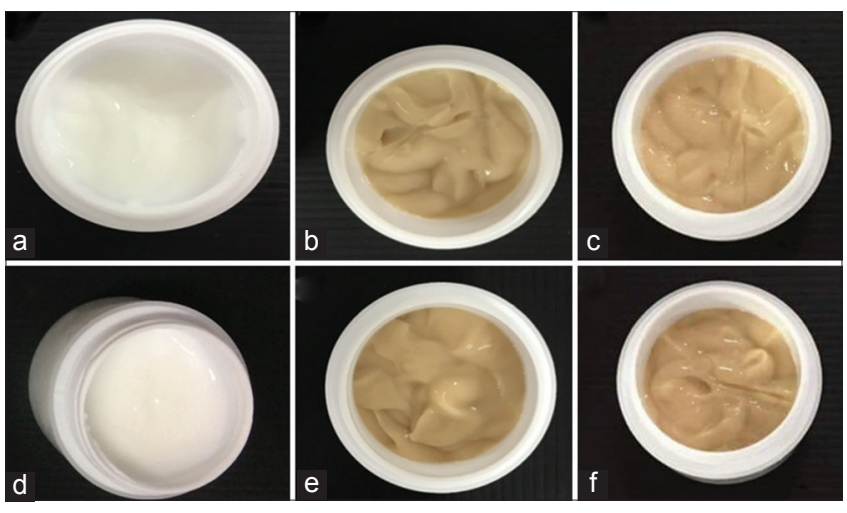

Fig. 2: The representative picture of body lotion made with arabica coffee extract (a): Formula 1, (b): Formula 2, (c):

Formula 3 and civet coffee extract (d): Formula 1, (e): Formula 2, (f): Formula 3

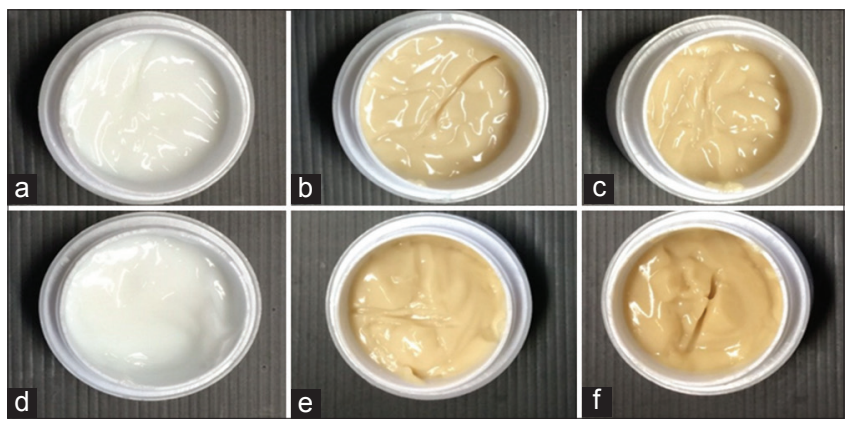

Fig. 3: The representative picture of hand moisturizing cream made with Arabica coffee extract (a): Formula 1, (b): Formula 2, (c): Formula 3 and civet coffee extract (d): Formula 1, (e): Formula 2, (f): Formula 3 preparation, and critical revision of the manuscript. JS, SS, NM, and SP are responsible for wet lab experiments and data collection. All the authors agree with the content of the manuscript.

\section{CONFLICTS OF INTEREST}

There is no conflict of interests.

\section{REFERENCES}

1. Ludwig IA, Clifford MN, Lean ME, Ashihara H, Crozier A. Coffee: Biochemistry and potential impact on health. Food Funct 2014;5:1695- 717 .

2. Farah A. Coffee constituents. In: Chu Y, editor. Coffee: Emerging Health Effects and Disease Prevention. $1^{\text {st }}$ ed. U.S.A: Blackwell Publishing Ltd; 2012. p. 21-58.

3. Belitz HD, Grosch M, Schieberle P. Food Chemistry. $4^{\text {th }}$ ed. Berlin: Springer-Verlag; 2009.

4. Mazzafera P. Chemical composition of defective coffee beans. Food Chem 1999;64:547-54.

5. Hu Q, Zhou T, Zhang L, Fang Y. Study of the separation and determination of monosaccharides in soluble coffee by capillary zone electrophoresis with electrochemical detection. Analyst 2001;126:298- 301.

6. Kurzrock T, Speer K. Diterpenes and diterpene esters in coffee. Food Rev Int 2001;17:433-50.

7. Ali M, Homann T, Kreisel J, Khalil M, Puhlmann R, Kruse HP, et al. Characterization and modeling of the interactions between coffee storage proteins and phenolic compounds. J Agric Food Chem 2012;60:11601-8.

8. Moura-Nunes N, Perrone D, Farah A, Donangelo CM. The increase in human plasma antioxidant capacity after acute coffee intake is not associated with endogenous non-enzymatic antioxidant components. Int J Food Sci Nutr 2009;60:173-81.

9. Herman A, Herman AP. Caffeine's mechanisms of action and its cosmetic use. Skin Pharmacol Physiol 2013;26:8-14.

10. Chaiyasut C, Kesika P, Chaiyasut K, Sittiyuno P, Peerajan S, Sivamaruthi BS. Total phenolic content and free radical scavenging activity of representative medicinal plants of Thailand. Asian J Pharm Clin Res 2017;10:137-41.

11. Sirilun S, Sivamaruthi BS, Kumar N, Kesika P, Peerajan S, Chaiyasut C. 
Lactobacillus-fermented plant juice as a potential ingredient in cosmetics: Formulation and assessment of natural mouthwash. Asian J Pharm Clin Res 2016;9:52-6.

12. Sirilun S, Chaiyasut C, Sivamaruthi BS, Peerajan S, Kumar N, Kesika P. Phenethyl alcohol is an effective non-traditional preservative agent for cosmetic preparations. Asian J Pharm Clin Res 2017;10:129-33.

13. Chaiyasut C, Sivamaruthi BS, Peerajan S, Sirilun S, Chaiyasut K, Kesika P. Assessment of heavy metals, minerals, alcohol, and fusel oil content of selected fermented plant beverages of Thailand. Int Food Res J 2017;24:126-33.

14. Pattananandecha T, Sirilun S, Duangjitcharoen Y, Sivamaruthi BS, Suwannalert P, Peerajan S, et al. Hydrolyzed inulin alleviates the azoxymethane-induced preneoplastic aberrant crypt foci by altering selected intestinal microbiota in Sprague-Dawley rats. Pharm Biol 2016;54:1596-605.

15. Chaiyasut C, Pattananandecha T, Sirilun S, Suwannalert P, Peerajan S, Sivamaruthi BS. Synbiotic preparation with lactic acid bacteria and inulin as a functional food: In vivo evaluation of microbial activities, and preneoplastic aberrant crypt foci. Food Sci Technol (Campinas) 2017;37:328-36.

16. Mohamed MK, Khalaf MM, Abo-Youssef AM, Abo-Saif AA. Caffeine as a promising antifibrotic agent against CCl4-induced liver fibrosis. Int J Pharm Pharm Sci 2017;9:42-7.

17. Islam MT, Alencar MV, Mata AM, Paz MF, Matos LA, Sousa JM, et al. Coffee: A health fuel-blot popular drinking. Int J Pharm Pharm Sci 2016;8:1-7.

18. Bhaktha G, Shantaram M, Nayak S. Beneficial effects of coffee and maintenance of uric acid levels. Int J Pharm Pharm Sci 2016:8:393-5.

19. Iriondo-DeHond A, Martorell P, Genovés S, Ramón D, Stamatakis K,
Fresno M, et al. Coffee silverskin extract protects against accelerated aging caused by oxidative agents. Molecules 2016;21:E721.

20. Rodrigues F, Palmeira-de-Oliveira A, das Neves J, Sarmento B, Amaral MH, Oliveira MB, et al. Coffee silverskin: A possible valuable cosmetic ingredient. Pharm Biol 2015;53:386-94.

21. Rodrigues F, Pereira C, Pimentel FB, Alves RC, Ferreira M, Sarmento B, et al. Are coffee silverskin extracts safe for topical use? An in vitro and in vivo approach. Ind Crops Prod 2015;63:167-74.

22. Wagemaker TA, Rijo P, Rodrigues LM, Maia Campos PM, Fernandes AS, Rosado C, et al. Integrated approach in the assessment of skin compatibility of cosmetic formulations with green coffee oil. Int J Cosmet Sci 2015:37:506-10.

23. Acevedo F, Rubilar M, Scheuermann E, Cancino B, Uquiche E, Garces $\mathrm{M}$, et al. Spent coffee grounds as a renewable source of bioactive compounds. J Biobased Mater Bio 2013;7:1-9.

24. Choi B, Koh E. Spent coffee as a rich source of antioxidative compounds. Food Sci Biotechnol 2017;26:921-7.

25. Kim JH, Ahn DU, Eun JB, Moon SH. Antioxidant effect of extracts from the coffee residue in raw and cooked meat. Antioxidants (Basel) 2016;5.

26. Nosaria AB, Lima JF, Serra OA, Freitas LA. Improved green coffee oil antioxidant activity for cosmetical purpose by spray drying microencapsulation. Rev Bras Farm 2015;25:307-11.

27. Page JC, Arruda NP, Freitas SP. Crude ethanolic extract from spent coffee grounds: Volatile and functional properties. Waste Manag 2017;69:463-9.

28. Ribeiro H, Marto J, Raposo S, Agapito M, Isaac V, Chiari BG, et al. From coffee industry waste materials to skin-friendly products with improved skin fat levels. Eur J Lipid Sci Technol 2013;115:330-6. 